\title{
- Ensino em Administração: análise à luz da abordagem das competências
}

\author{
Simone Costa Nunes ${ }^{1}$
}

\section{Resumo}

Este trabalho tem como objetivo analisar a inserção da noção de competências no ensino superior em nível de graduação, tendo sido escolhido o curso de Administração como objeto de análise. Trata-se de pesquisa qualitativa e descritiva, baseada em estudo de caso e dividida em três fases. Em todas as fases foram realizadas entrevistas semiestruturadas, totalizando cinco pessoas entrevistadas entre coordenador de curso, coordenador pedagógico e consultor. Os dados foram tratados conforme o método de análise de conteúdo, tendo sido previamente estabelecidas as categorias de análise. Os resultados apontam para uma possível ausência de clareza quanto ao significado de competências e habilidades; falta de articulação entre as habilidades que se propõe desenvolver no aluno e a intenção explicitada de formação; centralização do conhecimento no professor; foco na transmissão de conhecimento em detrimento da formação de competências; dificuldades para a operacionalização do modelo de formação baseado em competências. Pode-se concluir que, a despeito da identificação de habilidades a serem reveladas pelos alunos ao final do curso, não havia uma norma de competência que subsidiasse o processo de formação. Havia indícios, de um lado, da presença de alguns dos elementos da Pedagogia das Competências no curso pesquisado; de outro, isso não significava que houvesse uma orientação sistematizada e articulada, de forma global, entre todos os elementos que compunham o processo de ensino-aprendizagem.

Palavras-chave: Ensino em administração. Abordagem das competências. Processo de ensino-aprendizagem.

\section{Introdução}

A ideia de que a sobrevivência no mercado de trabalho depende da aquisição de mais e/ou novas competências vem se propagando no Brasil,

\footnotetext{
${ }^{1}$ Doutora em Administração pela Universidade Federal de Minas Gerais. Professora no Programa de Pós-graduação em Administração/Pontifícia Universidade Católica de Minas Gerais - PUC-MG. Endereço: Av. Itaú, 525-Bairro Dom Cabral - Belo Horizonte - MG - Brasil. CEP $30535-012$. E-mail: sinunes@pucminas.br.

Artigo recebido em: 18/04/2010. Aceito em: 14/10/2010. Membro do Corpo Editorial Científico responsável pelo processo editorial: Martinho Isnard Ribeiro de Almeida.
} 
especialmente nas duas últimas décadas. Tem sido cada vez mais demandado um profissional que apresente conhecimentos atualizados, competência técnica, iniciativa, capacidade crítica e de inovação, além de ser capaz de lidar com novas informações, entre outros (BRASIL, 1998).

Essa discussão se expande para o campo da formação e da educação, pois como explica Handfas (2001), o novo cenário impõe

[...] a necessidade de superação de um modelo de formação [...] baseado na aquisição de habilidades necessárias ao desempenho das tarefas de cada posto de trabalho $e$ aponta para outro, que traduza os requisitos necessários para a formação geral do trabalhador e sua maior capacidade de pensamento teórico-abstrato e lógico-matemático (HANDFAS, 2001, p. 5).

A esse respeito, Gonczi (1996) acrescenta que as diferenças entre o tipo de educação que se buscava em um contexto de produção em série e o que se busca hoje indicam que existe a necessidade de capacitação de um número maior de pessoas aptas a assumir trabalhos novos que requerem níveis mais elevados de competência.

$\mathrm{O}$ vínculo entre a oferta de formação e a demanda por profissionais ditos competentes procede de várias vertentes, com objetivos específicos, tais como: do sistema produtivo - pressão por elevação nos níveis de qualificação; das instituições governamentais e privadas de ensino e formação - ampliação das oportunidades e aproximação do mundo do trabalho; da comunidade internacional - padronização e normalização de procedimentos ocupacionais e reconhecimento de competências tácitas do trabalhador, da segurança e saúde no trabalho e da questão da diversidade; e dos órgãos sindicais - estabelecimento da certificação das competências como espaço de negociação e ampliação do leque de qualificações, a fim de criar mais oportunidades de emprego (BRÍGIDO, 1999).

As transformações necessárias à adequação do ensino a essa nova realidade vêm sendo discutidas em nível internacional. É assim, no bojo desse debate, que a noção de competências ocupa espaço privilegiado, tendo sido eleita como perspectiva pedagógica para a implementação da reforma educacional em diversos países, entre os quais se inclui o Brasil.

Diante desse cenário, surgiu o interesse pelo tema do presente trabalho, cujo objetivo é analisar a inserção da noção de competências no ensino 
superior em nível de graduação. Para tanto, foi escolhido o curso de Administração como objeto de análise.

A abordagem metodológica adotada foi do tipo qualitativo-descritiva. O método refere-se a estudo de caso, realizado em três fases, sendo a primeira delas um estudo piloto. A coleta de dados ocorreu a partir de um roteiro de entrevista semiestruturado. As entrevistas foram gravadas, transcritas, tratadas e analisadas segundo o método de análise de conteúdo, tendo-se estabelecido previamente as categorias de análise.

Os resultados apontam para uma possível ausência de clareza quanto ao significado de competências e habilidades; falta de articulação entre as habilidades que se propõem desenvolver no aluno e a intenção explicitada de formação; centralização do conhecimento no professor; foco na transmissão de conhecimento em detrimento da formação de competências; dificuldades para a operacionalização do modelo de formação baseado em competências. Pode-se concluir que, a despeito da identificação de habilidades a serem reveladas pelos alunos ao final do curso, não havia uma norma de competência que subsidiasse o processo de formação. Havia indícios, de um lado, da presença de alguns dos elementos da Pedagogia das Competências no curso pesquisado; de outro, isso não significava que havia uma orientação sistematizada e articulada, de forma global, entre todos os elementos que compunham o processo de ensino-aprendizagem.

Este trabalho encontra-se estruturado da seguinte maneira: após esta apresentação é feita breve menção à noção de competências seguida do resgate teórico sobre a formação baseada em competências e a Pedagogia das Competências. Na seção 5 são apresentados os procedimentos metodológicos da pesquisa. Na seção 6, o caso é descrito; na seção 7 é feita a análise dos dados e na seção 8 são relatadas as conclusões. As referências utilizadas são apresentadas no final.

\section{A Noção de Competências}

Uma expressiva quantidade de conceitos e enfoques adotados para a noção de competências pode ser encontrada na literatura. Isso demonstra a heterogeneidade com que o assunto é tratado em diferentes esferas de atividades, como o trabalho e a educação (DIAS, 2008). 
No âmbito do trabalho, o tema vem sendo estudado tanto no plano organizacional, sob a ótica da gestão estratégica (BECKER; DUTRA; RUAS, 2008; FLEURY; FLEURY, 2004; JAVIDAN, 1998; LEI; HITT; BETTIS, 2001; PRAHALAD; HAMEL, 1995), quanto em nível individual, que inclui a gestão de pessoas (BOYATZIS, 1982; DUTRA, 2008; LE BOTERF, 2003; ZARIFIAN, 2001).

Na esfera da educação, os estudos enfatizam diferentes aspectos, tais como a formação de currículos, o processo de ensinar e aprender, a avaliação e as competências docentes, além do enfoque privilegiado na educação profissional, entre outros temas. Exemplos de estudos nesse campo são os de Araújo (2001), Moretto (2009), Perrenoud (1999), Ropé e Tanguy (2003), Rué, Almeida e Arantes (2009), Silva (2008), Zabala e Arnau (2007).

A análise de diversos conceitos atribuídos ao tema permite considerar que "a competência é inseparável da ação" (ROPÉ; TANGUY, 2003, p. 16). Ou, como afirma Perrenoud (1999, p. 10), a construção de competências "é inseparável da formação de esquemas de mobilização dos conhecimentos com discernimento, em tempo real, ao serviço de uma ação eficaz".

Para fins do estudo que se apresenta entende-se como adequada a síntese apresentada por Zabala e Arnau (2007), que reúne as principais ideias sobre a noção de competências. Segundo eles, a competência refere-se à capacidade ou habilidade para realizar tarefas ou atuar frente a situações diversas, de forma eficaz, em um determinado contexto. Para isso é necessário mobilizar conhecimentos, habilidades e atitudes, ao mesmo tempo e de forma inter-relacionada. O conhecimento refere-se ao saber. As habilidades dizem respeito ao saber fazer, que está relacionado com a prática do trabalho. As atitudes referem-se ao saber ser.

\section{Onfoque da Formação Baseada em Competências}

O enfoque da formação baseada em competências tem suas raízes na década de 1920, nos Estados Unidos, embora só tenha ganhado destaque a partir da década de 1960, quando foi retomado o debate clássico do distanciamento entre o ensino acadêmico e a realidade da vida e do trabalho (OIT, 1999).

McClelland é citado como o responsável pela origem do conceito. Ele argumentou que os tradicionais exames acadêmicos não garantiam o desem- 
penho no trabalho e nem o êxito na vida. Dessa forma, era necessário buscar outras variáveis - competências - que pudessem melhor predizer os resultados (MERTENS, 1996; TRUJILLO, 2000; VARGAS; CASANOVA; MONTANARO, 2001). Foi assim que surgiu, na década de 1970, o movimento denominado "Ensino baseado em competências".

O enfoque nas competências profissionais distingue quatro dimensões, que representam a aplicação prática da noção de competências: identificação, normalização, formação e certificação (CINTERFOR, 2004).

A identificação de competências refere-se ao processo que estabelece, a partir de uma atividade de trabalho, as competências necessárias para o desempenho dessa mesma atividade, de maneira satisfatória (CINTERFOR, 2004). Consiste em uma análise qualitativa do trabalho, que visa descrever os conhecimentos, as habilidades, as destrezas e a compreensão que o trabalhador mobiliza para desempenhar efetivamente uma função (VARGAS; CASANOVA; MONTANARO, 2001).

O resultado do processo de identificação é o estabelecimento de um perfil de competências, que se converte em norma ou padrão.

A normalização de competências pode ser entendida como a expressão escrita e formalizada de conhecimentos, habilidades, destrezas e a compreensão que o trabalhador deve mobilizar para desempenhar a contento uma atividade de trabalho.

Uma norma compreende o que a pessoa deve ser capaz de fazer, a forma de julgamento do desempenho em relação ao padrão estabelecido, as condições em que a pessoa deve demonstrar sua competência e os tipos de evidências necessários e suficientes para assegurar que o desempenho tenha sido consistente, com base em um conhecimento efetivo.

No desenho da formação devem ser estabelecidos os módulos, as pautas de requisitos do corpo docente, os espaços, os recursos didáticos, as metodologias, os recursos tecnológicos e as atividades profissionais, com os critérios de realização (VARGAS; CASANOVA; MONTANARO, 2001).

Feita a descrição das competências e a sua normalização, a elaboração de currículos de formação para o trabalho será muito mais eficiente se considerada a orientação da norma.

Para orientar a formação, os conteúdos, as metodologias e a avaliação deveriam concentrar-se no marco pedagógico que contemple a aquisição de cada uma das competências requeridas segundo o perfil estabelecido. Para isso, é necessário que as estratégias pedagógicas sejam mais flexíveis que as 
tradicionalmente utilizadas (CINTERFOR, 2004; VARGAS; CASANOVA; MONTANARO, 2001).

A certificação de competências diz respeito ao ato mediante o qual se reconhece a competência demonstrada pelo trabalhador. Implica uma avaliação prévia, usualmente em função dos requerimentos da norma de competência. Essa avaliação serve de diagnóstico, pois compara o desempenho com o padrão estabelecido. Nesse sentido, a avaliação apresenta-se como um processo crucial para a certificação.

\section{A Pedagogia das Competências}

A Pedagogia das Competências se propõe a orientar práticas educativas que tenham por objetivo o desenvolvimento das capacidades necessárias ao exercício profissional nas condições atuais colocadas pelo mundo do trabalho (ARAÚJO, 2001).

Esse modelo pedagógico pode ser entendido a partir dos elementos que o compõem tendo sido privilegiados, para efeitos deste trabalho, aspectos como os objetivos do processo de formação, a organização curricular, os métodos de ensino, a articulação teoria/prática, os papéis dos sujeitos e a avaliação. Esses assuntos são abordados a seguir.

A formação é definida em termos de competências terminais exigíveis ao final do curso, ano, ciclo ou formação, as quais são explicitamente detalhadas e descritas em termos de saberes e ações (ARAÚJO, 2001; TANGUY, 2003).

Aos conteúdos formativos são incorporados elementos do saber fazer e do saber ser. Assim, passam a se constituir não só "dos conhecimentos teóricos formalizados nas matérias e disciplinas, mas de atitudes, comportamentos, hábitos, posturas, elementos que possam compor uma capacidade de trabalho" e que remetem a um saber, a um saber fazer e a um saber ser vinculados a um contexto específico (ARAÚJO, 2001, p.16).

A formação por competências defende a passagem de um ensino centrado nos saberes disciplinares para um ensino que produza competências verificáveis em situações e tarefas específicas (TANGUY, 2003).

No entanto, o desenvolvimento de competências na escola não leva a uma renúncia às disciplinas, uma vez que as competências mobilizam conhecimentos que são, em grande parte, de ordem disciplinar. Dessa forma as 
competências são desenvolvidas tanto dentro das disciplinas quanto na sua interseção, trabalhando-se a transferência e mobilização de conhecimentos em situações complexas (PERRENOUD, 1999).

Corroborando com essa visão, Berger Filho (2003) acrescenta que é necessário superar o dilema de centralização da aprendizagem nos conhecimentos ou nas competências. A diferença que se estabelece na proposição curricular baseada em competências é que no centro do currículo - e, logo, da prática pedagógica - não está a transmissão de saberes, mas o processo de construir, apropriar e mobilizar esses saberes.

Enfatiza-se a noção de currículo integrado com vistas à compreensão global do conhecimento. Nesse sentido, alguns princípios curriculares são considerados importantes, tais como a interdisciplinaridade e a contextualização (RAMOS, 2002).

O ensino baseado na interdisciplinaridade possibilita aos alunos maior capacidade para o enfrentamento de "problemas que transcendem os limites de uma disciplina concreta e para detectar, analisar e solucionar problemas novos" (SANTOMÉ, 1998, p.74).

A contextualização deve ocorrer por meio de experiências de aprendizagem concretas e práticas, focadas em atividades que se realizam nos contextos ou situações reais. Seu objetivo é propiciar uma "aprendizagem significativa ao associá-la às experiências da vida cotidiana ou com conhecimentos adquiridos espontaneamente e, assim, retirar o aluno da condição de espectador passivo" (RAMOS, 2002, p. 141). Dessa maneira, depara-se com a questão de desenvolver capacidades em ambientes que estimulem a busca de soluções para os problemas e que produzam a autonomia do aluno.

Os currículos devem ser então, direcionados para desenvolver a capacidade de resolução de problemas, compreendendo conhecimentos gerais e profissionais, e a experiência de trabalho. Isso pressupõe privilegiar o método de ensino por problema. Tal método permite mobilizar, de forma combinada, conhecimentos, habilidades e atitudes em situações autênticas ou parecidas com a realidade (ARAÚJO, 2001).

Perrenoud (1999, p. 57) não fala simplesmente em problemas "para insistir no fato de que, para ser 'realista', um problema deve estar de alguma maneira 'incluído' em uma situação que lhe dê sentido", pois a escola tem proposto, há várias gerações, para os estudantes, problemas artificiais e descontextualizados. A situação-problema deve colocar o aluno diante de 
uma série de decisões a serem tomadas, visando ao alcance de um objetivo que ele mesmo escolheu ou que lhe foi proposto.

Essa Pedagogia privilegia as práticas de trabalho em grupo, as dramatizações e os seminários voltados ao desenvolvimento das capacidades desejadas. Recursos como esses possibilitam "estimular a autonomia e a capacidade de trabalhar sem que se tenham definidos os passos a serem seguidos" (ARAÚJO, 2001, p. 52). Além disso, sugere-se como meio de ensino e recurso didático, o uso dos mesmos instrumentos empregados em atividades de trabalho.

Como uma das formas de aproximar teoria e prática, tal modelo pedagógico pressupõe práticas de alternância, que objetivam intercalar os períodos de formação realizados em empresas com outros, cumpridos em instituições específicas de educação (ARAÚJO, 2001). Como afirmam Ropé e Tanguy (2003):

[...] a atividade de formação, [...] ao se desenvolver, deslocou-se de lugares especializados nessa função - como a escola - para outros lugares e em especial para as empresas que, tendencialmente, tornam-se lugares e agentes de formação e não só de produção de bens ou de serviços materiais ou culturais (ROPÉ; TANGUY, 2003, p. 18).

O aluno é colocado no centro do processo educativo e o professor passa a ser visto como organizador das situações de aprendizagem, "mais do que como distribuidor de saberes" (PERRENOUD, 2000, p. 45). Nesse sentido, deve haver uma redefinição dos papéis dos sujeitos da prática educativa. Do professor, espera-se uma transformação de sua relação com o saber, de sua forma de dar a aula, de sua própria identidade e de suas competências profissionais (PERRENOUD, 1999). Logo, atitudes de centralização do conhecimento em sua pessoa devem ser evitadas (ARAÚJO, 2001). Do aluno, é esperada maior responsabilidade em relação a seu próprio desenvolvimento de competências e ao seu sucesso ou fracasso (PERRENOUD, 1999).

O processo de avaliação deve pautar-se nas competências estabelecidas, que devem ser avaliadas por meio de critérios de desempenho previamente definidos (ARAÚJO, 2001; TANGUY, 2003). Isso significa privilegiar o desempenho ou a capacidade de aplicação e síntese do conhecimento, e não a sua aquisição propriamente dita. 
A formação por competências privilegia a aprendizagem em ritmo individual e gradual (RAMOS, 2002). Assim, a avaliação deve respeitar a individualidade do aluno, compreendendo o acompanhamento de todo o processo de ensino/aprendizagem, desde o seu ingresso no curso. Devem ser identificadas as necessidades e dificuldades do estudante para, desta forma, propor estratégias capazes de superar dificuldades. Logo, a avaliação deve caracterizar-se como processual e formativa (FERNANDES et al., 2005).

Perrenoud (1999) acrescenta que o professor não deve avaliar por meio de comparações entre alunos, e sim, por meio de comparações entre a tarefa a realizar, o que o aluno fez e o que faria se fosse mais competente. Os mesmos indicadores de competências devem, então, ser levados em conta, porém em estágios diferentes de sua construção. E o professor deve estar ciente de que no fim do período letivo a avaliação será certificativa.

\section{Procedimentos Metodológicos}

A pesquisa foi desenvolvida a partir de uma abordagem metodológica do tipo qualitativo-descritiva. Justifica-se essa escolha tendo em vista seu objetivo, privilegiando-se um método tão aberto que fizesse justiça à complexidade do objeto de estudo.

Dividida em três fases, a pesquisa refere-se a um estudo de caso, sendo que a primeira fase pode ser caracterizada como um estudo de caso piloto.

O estudo de caso piloto consiste em uma investigação muito mais ampla e menos direcionada do que o plano final para a coleta dos dados. Ele auxilia o pesquisador a aprimorar os planos de coleta de dados no que se refere ao conteúdo dos dados e também quanto aos procedimentos que devem ser seguidos, bem como ajuda a desenvolver o alinhamento relevante das questões (YIN, 2001).

Para efeito desta pesquisa, o estudo piloto teve como finalidade fornecer melhor visão das questões básicas a serem tratadas, possibilitando ao pesquisador maior familiaridade com o fenômeno que seria investigado em um estudo subsequente de contextura mais elevada. Nesse sentido, a primeira fase teve caráter mais exploratório, conforme definição de Selltiz et al. (1965).

A escolha do método estudo de caso ocorreu tendo em vista o objetivo de aprofundar a descrição da realidade (GIL, 1996). Segundo Triviños (1987, p.11) "o grande valor do estudo de caso: fornecer o conhecimento 
aprofundado de uma realidade delimitada que os resultados atingidos podem permitir e formular hipóteses para o encaminhamento de outras pesquisas."

A escolha do caso ocorreu a partir de uma pesquisa realizada entre 2003 e 2007 sobre a inserção da noção de competências em cursos de graduação em Administração que envolveu 19 cursos de 12 Instituições de Educação Superior (IES) localizadas em Belo Horizonte, Minas Gerais. Tal estudo foi dividido em três fases. Para fins do presente trabalho, optou-se por apresentar apenas aquele caso que se mostrou como mais significativo diante dos objetivos propostos. Nesse curso, além da presença, no projeto pedagógico, de competências a serem desenvolvidas, os planos de ensino das disciplinas as contemplavam e detalhavam, na expectativa de que os conteúdos se voltassem ao seu desenvolvimento.

O caso refere-se ao curso de Administração de Empresas de uma IES privada que teve seu funcionamento iniciado no segundo semestre de 1998.

A técnica de coleta de dados escolhida foi a entrevista semiestruturada, devido às suas características de flexibilidade e adaptabilidade, possibilitando que novos questionamentos fossem introduzidos à medida que as respostas fossem dadas pelos entrevistados.

Foram realizadas três entrevistas com um total de cinco pessoas, sendo dois coordenadores de curso, dois coordenadores pedagógicos e um consultor. Na primeira e na terceira fase da pesquisa, a entrevista ocorreu com duas pessoas, simultaneamente. Não se fez, contudo, distinção entre os dois entrevistados, pois suas falas se misturaram. Ou seja, um costumava completar a resposta do outro ou então a confirmava com outras palavras. Não houve divergência de opiniões entre eles. Assim, os entrevistados receberam os seguintes códigos: E1, E2 e E3.

Os dados foram analisados a partir do método de análise de conteúdo, tendo-se estabelecido previamente as categorias de análise.

Além desses aspectos, o presente estudo tem as seguintes características (Quadro 1): 


\begin{tabular}{|c|c|c|c|c|c|}
\hline Fase & $\begin{array}{l}\text { Ano coleta } \\
\text { de dados }\end{array}$ & Objetivo & $\begin{array}{l}\text { Entrevistados } \\
\text { / Quantidade }\end{array}$ & $\begin{array}{c}\text { Código } \\
\text { Entrevistado }\end{array}$ & $\begin{array}{c}\text { Categorias de } \\
\text { análise }\end{array}$ \\
\hline $1^{a}$ & 2003 & $\begin{array}{l}\text { Identificar se a } \\
\text { noção de compe- } \\
\text { tências estava } \\
\text { inserida na lógica } \\
\text { do curso } \\
\text { pesquisado, bem } \\
\text { como demonstrar } \\
\text { como tal noção } \\
\text { vinha norteando, } \\
\text { de forma ampla, a } \\
\text { elaboração do } \\
\text { currículo e a } \\
\text { organização } \\
\text { acadêmica desse } \\
\text { curso }\end{array}$ & $\begin{array}{l}\text { Coordenador } \\
\text { do curso / } 1 \\
\text { Consultor / } 1\end{array}$ & E1 & $\begin{array}{l}\text { Adoção da noção de } \\
\text { competências } \\
\text { Competências a } \\
\text { serem desenvolvidas } \\
\text { Conceito adotado } \\
\text { Perfil do egresso } \\
\text { Importante para } \\
\text { desenvolver compe- } \\
\text { tências } \\
\text { Aferição da aquisi- } \\
\text { ção de competências } \\
\text { Articulação entre } \\
\text { competências e } \\
\text { matriz curricular }\end{array}$ \\
\hline $2^{\mathrm{a}}$ & 2005 & $\begin{array}{l}\text { Mapear os } \\
\text { aspectos que } \\
\text { caracterizam a } \\
\text { inserção da noção } \\
\text { de competências } \\
\text { quanto à identifi- } \\
\text { cação, normaliza- } \\
\text { ção, formação e } \\
\text { avaliação }\end{array}$ & $\begin{array}{l}\text { Coordenador } \\
\text { do curso / } 1 \\
\text { (não era o } \\
\text { mesmo da } 1^{\text {a }} \\
\text { fase; assumiu } \\
\text { o cargo em } \\
\text { agosto de } \\
2005 \text { ) }\end{array}$ & E2 & $\begin{array}{l}\text { Identificação } \\
\text { Normalização } \\
\text { Formação } \\
\text { Avaliação } \\
\text { Considerações sobre } \\
\text { o uso da noção de } \\
\text { competências }\end{array}$ \\
\hline $3^{a}$ & 2006 & $\begin{array}{l}\text { Mapear os } \\
\text { aspectos que } \\
\text { caracterizam a } \\
\text { Pedagogia das } \\
\text { Competências } \\
\text { nos cursos } \\
\text { investigados }\end{array}$ & $\begin{array}{l}\text { Coordenador } \\
\text { pedagógico / } 2\end{array}$ & E3 & $\begin{array}{l}\text { Organização } \\
\text { curricular } \\
\text { Métodos de ensino/ } \\
\text { aprendizagem } \\
\text { Processo de avaliação } \\
\text { Papéis dos sujeitos } \\
\text { (docente e discente) }\end{array}$ \\
\hline
\end{tabular}

Quadro 1: As três fases da pesquisa

Fonte: Dados da pesquisa 


\section{Curso de Administração sob a Ótica das Competências}

\subsection{Estudo de caso piloto: primeira fase da pesquisa}

A primeira fase da pesquisa buscou identificar se a noção de competências estava inserida na lógica do curso pesquisado, bem como demonstrar como tal noção vinha norteando, de forma ampla, a elaboração do currículo e a organização acadêmica desse curso, conforme apresentado a seguir.

A inserção da noção de competências no projeto pedagógico ocorreu à época da criação do curso. A primeira turma teve início no segundo semestre de 1998.

O curso estava voltado para a formação da competência empreendedora. Esperava-se formar um aluno capaz de montar o seu próprio negócio ou de atuar nas organizações de forma empreendedora.

No Manual do Aluno do ano de 2003 havia a seguinte menção à noção de competências: "[...] compromisso de orientar o aluno na construção de suas habilidades e competências. [...] necessárias à sua profissionalização" (CENTRO DE GESTÃO EMPREENDEDORA, 2003, p. 37).

Nesse Manual, o que se encontrou foi uma lista de habilidades genéricas que deveriam ser desenvolvidas nos alunos. Essas habilidades eram as mesmas para todos os sete cursos oferecidos pela IES, pertencentes a várias áreas do conhecimento. São elas:

- comunicação interpessoal, expressão correta nos documentos técnicos específicos e interpretação da realidade das organizações;

- utilização de raciocínio lógico, crítico e analítico, operando com valores e formulações matemáticas e estabelecendo relações formais e causais entre fenômenos;

- interação criativa face aos diferentes contextos organizacionais e sociais;

- compreensão do todo administrativo, de modo integrado, sistêmico e estratégico, bem como de suas relações com o ambiente externo; 
- capacidade para lidar com modelos inovadores de gestão;

- resolução de problemas e desafios organizacionais com flexibilidade e adaptabilidade;

- ordenação de atividades e programas, identificando $e$ dimensionando riscos para tomada de decisões;

- seleção de estratégias adequadas de ação, visando ao atendimento de interesses interpessoais e institucionais;

- seleção de procedimentos que privilegiem formas de atuação em prol de objetivos comuns (CENTRO DE GESTÃO EMPREENDEDORA, 2003, p. 9).

Não havia no projeto pedagógico do curso um perfil de egresso que deveria ser formado. Além disso, não foi encontrado um conceito sobre o que seria "competência" para o curso.

Em relação à articulação entre a "competência empreendedora" e a matriz curricular, os entrevistados (E1) apenas disseram que esta foi gerada para a formação da cultura empreendedora.

Para desenvolver tal "competência" nos alunos, foram considerados importantes o trabalho interdisciplinar, que ocorria em cada um dos períodos do curso; os jogos de empresas; a participação em feiras de empreendedores; a realização de trabalhos extracurriculares; as visitas técnicas; e a preocupação da IES em mostrar ao aluno a relação entre a faculdade e o mundo.

Entendia-se que habilidades e competências deviam ser "refinadas $e$ desenvolvidas" também fora da sala de aula (CENTRO DE GESTÃO EMPREENDEDORA, 2003, p. 38). Para que isso pudesse ocorrer, foi criado um órgão específico para a orientação de alunos na prática do estágio supervisionado e a gestão da Empresa Júnior.

Sobre os mecanismos para se verificar se as competências tinham sido desenvolvidas nos alunos, os entrevistados (E1) citaram uma forma indireta de avaliação, vinda do mercado: o acompanhamento da inserção do aluno no mercado de trabalho.

Os resultados obtidos a partir desse estudo piloto permitiram verificar que a noção de competências estava de alguma forma inserida na lógica do curso pesquisado. Assim, partiu-se para as fases seguintes da pesquisa. 


\subsection{Segunda e terceira fase da pesquisa}

A segunda fase da pesquisa buscou mapear os aspectos que caracterizam a inserção da noção de competências no curso quanto à identificação, normalização, formação e avaliação. A terceira fase teve como objetivo mapear aspectos relacionados à Pedagogia das Competências.

Essas duas fases são apresentadas conjuntamente, na sequência. Optou-se por essa forma de apresentação por se acreditar que isso simplificaria o entendimento dos processos de formação e avaliação, ambos investigados na segunda fase e aprofundados na terceira.

No primeiro semestre de 2004, uma nova estrutura curricular foi implementada, porém não foi possível saber se o projeto pedagógico também havia sido modificado na mesma época. Ambos continuavam vigentes em setembro de 2006, quando foi realizada a terceira fase da coleta de dados.

No segundo momento da pesquisa ainda não havia um conceito para competências que fosse adotado pelo curso. O entrevistado (E2), por sua vez, entendia competências como

[...] a capacidade de mobilizar recursos diante de uma situação complexa, [...] quando a situação acontece. Então, tem dois aspectos que [...] eu associo ao conceito de competência, que são: ela não é algo que você constrói isolada da ação [...]. A competência se mostra na ação. Eu não consigo dissociar. E ela pode ser desenvolvida. Tem como ser desenvolvida, pra se apresentar na situação [...] (E2).

Um perfil para o egresso do curso foi identificado na coleta realizada em 2005. Tal perfil, basicamente, coincidia com aquele explicitado nas Diretrizes Curriculares Nacionais (DCN) do curso de graduação em Administração (Parecer CNE/CES n. 134/2003):

[...] capacitado a compreender questões científicas, técnicas, sociais e econômicas da produção e de seu gerenciamento, observados os níveis graduais do processo de tomada de decisão, de forma que demonstre flexibilidade intelectual $e$ adaptabilidade contextualizada no campo de atuação do administrador (BRASIL, 2003). 
As habilidades identificadas na primeira fase dessa pesquisa foram mantidas no projeto e sofreram desdobramento, nos planos de ensino das disciplinas, em três conjuntos básicos - habilidades conceituais (saber), procedimentais (saber fazer) e atitudinais (saber ser). Essas habilidades serviam de parâmetro para os professores estabelecerem os demais itens do plano de ensino, tais como os objetivos, o conteúdo programático e a avaliação.

Ficava a cargo da coordenação pedagógica a análise dos planos de ensino a fim de se certificar se atendiam à formação desses três conjuntos de habilidades.

O currículo do curso apresentava-se na forma de disciplinas, porém, a fim de evitar a sua compartimentação, era valorizada a interdisciplinaridade.

O trabalho interdisciplinar que era adotado quando da primeira fase da pesquisa já não existia mais no curso. A justificativa para a sua retirada refere-se a conflitos gerados em seu desenvolvimento, tendo em vista a presença de alunos irregulares nas turmas. Então, outras atividades foram valorizadas visando à interdisciplinaridade, tais como visitas técnicas, palestras e jogos. Esperava-se que as disciplinas envolvidas nessas atividades pudessem buscar para si o conteúdo daquela experiência.

Sobre isso, os entrevistados (E3) acrescentaram que havia dificuldades quanto ao tratamento desse conceito, como explicitado a seguir: "E a atividade da interdisciplinaridade que a gente não tem conseguido. [...] Por que, também, falta o quê? Um conhecimento do professor do que é esse trabalho interdisciplinar, o que que a gente chama de interdisciplinar" (E3).

Era uma sugestão no curso o uso de situações-problema. Eram utilizados os estudos de casos elaborados pelos próprios professores ou aqueles presentes em determinados livros adotados nas disciplinas. Esses casos diziam respeito a situações tanto reais quanto fictícias.

Para aproximar a teoria da prática, E2 falou sobre o corpo docente que, em parte, conjugava formação acadêmica sólida com formação profissional. Ele citou também as visitas técnicas, as palestras com profissionais de mercado e a Empresa Júnior. Os entrevistados (E3) acrescentaram os estudos de casos; a participação em feira de empreendedores, onde os alunos apresentavam projetos de negócios por eles desenvolvidos e os trabalhos dados pelos docentes.

Em relação à existência de momentos em que os alunos poderiam receber parte de sua formação em empresas, foi dito que a partir do $5^{\circ}$ período eles deveriam cumprir as horas de estágio supervisionado. 
O trabalho em equipe era valorizado no curso, pois se entendia que isso poderia levar o aluno a aprender a dividir e respeitar o outro. Exemplos de trabalhos que possibilitavam isso são os jogos de empresas e também os projetos desenvolvidos para a feira de empreendedores, que envolvia alunos já a partir do $1^{\circ}$ período, sendo ambos formalmente inseridos no curso.

Em relação aos métodos utilizados, os entrevistados (E3) falaram sobre: estudos de casos; aula "tradicional" (E3), ou seja, expositiva; e trabalhos a partir de filmes. Segundo eles, os professores definiam os métodos que seriam utilizados considerando que havia uma série de recursos disponíveis, como laboratório de informática, onde poderiam ser feitas simulações. A Coordenação, por seu lado, cobrava dos professores a utilização de procedimentos que estimulassem a atenção do aluno.

Os entrevistados não tinham informações a respeito da existência no curso de instrumentos que eram utilizados em atividades reais de trabalho.

Sobre a avaliação de alunos, era esperado que o professor verificasse, em todos os momentos, o desenvolvimento das habilidades conceituais, procedimentais e atitudinais colocadas. Assim, deveria haver da parte dos docentes a preocupação em elaborar todo o processo de aprendizado em função desse modelo, incluindo as avaliações.

No entanto, era perceptível que as avaliações acabavam privilegiando os conhecimentos em detrimento da aquisição de competências: "Geralmente, as provas que a gente pega, tá tudo dentro do conceito. [...] O que a gente tem sugerido? Vê se você consegue equilibrar, dentro da sua avaliação, conceitual, procedimental e atitudinal" (E3).

Havia a crença de que os professores avaliavam os alunos após a realização de cada atividade, pois tinham 25 pontos para distribuir em sala de aula, em "avaliações pequenininhas [...], que valem 5 pontos, [...] 3 pontos [...]" (E3). Cada uma delas não poderia valer mais do que nove pontos, para evitar que o professor ficasse muito tempo sem avaliar e acumulasse esses pontos em uma única avaliação. A expectativa do curso era de que a avaliação fosse processual. O restante dos pontos era distribuído em três provas, sendo uma de 20 pontos, outra de 25 e uma final de 30 pontos.

Alguns professores, quando identificavam dificuldades na aprendizagem a partir dos resultados obtidos nas provas, faziam uma nova avaliação após a revisão do conteúdo em questão. Mas havia também aqueles professores que não aceitavam fazer reavaliação de conteúdo. 
Em relação ao seu papel, os professores eram vistos como centralizadores do processo de ensino-aprendizagem. Entretanto, os entrevistados (E3) acreditavam que era importante que fosse dada autonomia ao aluno, conforme explicita o trecho a seguir: "[...] mas eu acho que seria imprescindível pra ele perceber esse aluno, trabalhar esse aluno de forma que ele seja autônomo, sim, dono do seu pensamento, dono do seu conhecimento [...]" (E3).

Esses entrevistados argumentaram que o comportamento dos professores era o reflexo de sua formação, como colocado pela fala a seguir: "... mesmo nas graduações, não existe essa metodologia. Então, ele acredita que se faz professor só no cotidiano. Foi assim que ele aprendeu: com exemplos de outros professores que eles tiveram" (E3).

O aluno deveria ser visto como sujeito de sua própria formação. Porém, não se consegue desenvolver essa cultura se os professores não estiverem envolvidos com esse mesmo pensamento: "Então, se o professor tem uma ideia que ele vai lá passar o conteúdo dele, o aluno também fica como mero [receptor]" (E3).

Por fim, algumas considerações foram feitas sobre o modelo de formação por competências. Segundo E2, a implementação e operacionalização desse modelo era difícil, "[...] dadas as especificidades de cada disciplina e a necessidade de integração disso num corpo só pra formar um egresso" (E2). E complementou: "[...] ainda existe um gap muito grande [...] do que se pensa em fazer, do que se propõe fazer, e o que efetivamente é feito [...]" (E2).

Apesar de todos os esforços no sentido de planejar o processo visando à formação das habilidades propostas pelo curso, ainda era preciso pensar em termos de sua implementação. Segundo a visão de E2, os planos de ensino estavam "já, até certo ponto, até bem evoluídos, eu diria, em termos estruturais, de papel" (E2). Porém, faltava implementar "[...] no dia-a-dia de sala de aula mesmo, trabalhar em cima desses critérios" (E2).

O entrevistado (E2) entendia que havia, da parte dos professores, uma dificuldade real de se colocar em prática esse modelo de formação, tanto em termos de desenvolver como de avaliar. Para E3 uma dificuldade encontrava-se na definição das atividades relacionadas ao desenvolvimento das habilidades, o que levava os professores a se manterem mais na parte conceitual.

Apesar de acreditar que alguns professores tinham avançado um pouco mais do que outros em direção ao modelo, todos teriam que estar envol- 
vidos no processo para que ele fosse realmente viabilizado. E acrescentou: "Hoje, eu não vejo continuamente isso acontecendo" (E2).

E acrescentou, finalmente, que a importância de se adotar a noção de competências no curso de Administração estava relacionada à "reintegração do conhecimento" (E2), o que significava superar a visão fragmentada do conhecimento, rompendo com o modelo taylorista de ensino. Porém, para que essas mudanças ocorressem, seriam necessárias alterações no próprio corpo docente, na forma como tinha aprendido a dar aula, para que pudesse incorporar esse novo modelo de formação.

\section{Análise e Considerações sobre os Achados da Pesquisa}

A análise dos resultados obtidos nas entrevistas, realizadas em três fases, é apresentada de maneira consolidada, na sequência.

Quando da concepção do projeto pedagógico, não havia sido formatado um perfil para o egresso. Contudo, na segunda fase da pesquisa foi identificado esse perfil, que correspondia àquele presente nas $\mathrm{DCN}$ do curso de graduação em Administração.

Desde a primeira fase da pesquisa foram identificadas habilidades que os alunos deveriam revelar ao final do curso. Não se pode afirmar, no entanto, que estas tenham sido detalhadas e descritas em termos de saberes e ações, pois no momento da pesquisa, os planos de ensino estavam sendo reconstruídos, pelos professores, com base no modelo de habilidades conceituais, procedimentais e atitudinais proposto pelo curso.

Nota-se, nesse caso, o uso do termo habilidades a se desenvolver, não competências. Isso pode ter ocorrido devido ao fato de o MEC apresentar nas DCN um rol de competências e habilidades requeridas ao egresso sem, contudo, separar ou diferenciar quais seriam competências e quais seriam habilidades. No Exame Nacional de Cursos (ENC-Provão), entre 1996 e 2003, por sua vez, aparecia apenas o termo habilidades aferidas, não competências.

Também se constata que o curso adotou a terminologia habilidades conceituais, procedimentais e atitudinais para definir os conteúdos de aprendizagem. Chama atenção o uso indiscriminado do termo habilidades. Considerando-se o conceito de Zabala e Arnau (2007), anteriormente apresenta- 
do, habilidades, juntamente com conhecimentos e atitudes, são meios que, mobilizados, possibilitam a competência.

Outro aspecto relevante diz respeito à falta de articulação entre as habilidades que se propõem desenvolver $e$ a intenção explicitada de formação de alunos empreendedores. O rol de habilidades apresentado pelo curso refere-se àquelas habilidades avaliadas pelo ENC-Provão, no curso de Administração. Além disso, a IES considerou as mesmas habilidades na formação de alunos dos outros seis cursos oferecidos. Ressalta-se que tais cursos eram de diferentes áreas do conhecimento.

Não havia um conceito que representasse para o curso o direcionamento dado pelas competências. Este pode ter sido outro motivo para o uso do termo habilidades, não competências a desenvolver nos alunos, refletindo falta de clareza quanto ao significado dos termos.

A matriz curricular havia sido construída como base no modelo tradicional, disciplinar. Era intenção do curso minimizar a compartimentação do conhecimento disciplinar por meio da introdução do conceito de interdisciplinaridade. No entanto, esse conceito precisava, ainda, ficar claro para os docentes, como afirmaram alguns entrevistados.

O curso orientava os professores no sentido de possibilitarem, aos alunos, tanto o trabalho em grupo quanto o trabalho sobre situações-problema. Havia aqueles docentes que se utilizavam de estudos de casos para este fim. O que não foi possível saber é se esses estudos realmente colocavam o aluno diante de situações em que deveriam tomar decisões ou se apenas serviam como exemplos que espelhavam as teorias trabalhadas pelos docentes em sala de aula.

Como forma de possibilitar, aos alunos, períodos de formação em empresas, foram citados os estágios curriculares. Além disso, para aproximar teoria e prática havia, entre outros, as visitas técnicas, a Empresa Júnior e a participação em feira de empreendedores.

O processo de avaliação era direcionado para o modelo processual. Contudo, não havia igualdade no tratamento dado a essa questão pelos professores. Além disso, era privilegiada a avaliação do conhecimento propriamente dito e não a sua aplicação.

Também não havia padronização de procedimento quanto ao caráter formativo da avaliação. Os professores podiam optar ou não por rever um conteúdo e aplicar nova avaliação quando verificadas deficiências nos alunos. 
De maneira geral, foi dito que não existiam meios internos, pré-definidos e capazes de mostrar os resultados do processo de formação. Entendiase que essa comprovação poderia vir de controles externos, tal como a inserção do aluno no mercado de trabalho. Com isso, constata-se que, apesar de esta IES certificar o aluno, ela não tinha meios próprios para garantir que ele tinha adquirido as habilidades que aquele mesmo certificado deveria comprovar. Assim, em vez de a IES fornecer ao mercado essa garantia, ela esperava que o mercado o fizesse.

Percebia-se também que a maioria dos docentes privilegiava a transmissão de conhecimentos, segundo a Coordenação de Curso e a Coordenação Pedagógica. Para esses entrevistados, a maior parte das provas envolvia saberes conceituais em detrimento do saber fazer (habilidades procedimentais) e do saber ser (habilidades atitudinais). Isso reforça a percepção quanto a se privilegiar a aquisição do conhecimento propriamente dito, em vez de se medirem desempenhos ou a capacidade de aplicação desse mesmo conhecimento, conforme propõe a abordagem para a formação baseada em competências.

Quanto ao seu papel, o professor ainda era visto como centralizador do conhecimento. Havia a crença de que os professores, em geral, tendiam a não trabalhar como facilitadores do processo, de forma a possibilitar a autonomia do aluno. Nesse sentido, os alunos não seriam estimulados a perceber a sua responsabilidade em relação a seu próprio desenvolvimento, ficando como meros receptores de conhecimento.

Alguns fatores foram considerados dificultadores da concretização da proposta do curso, entre eles a ausência de entendimento dos professores quanto ao conceito de interdisciplinaridade; a falta de clareza quanto às atividades que possibilitariam a formação das habilidades procedimentais $e$ atitudinais; a maneira de dar as aulas, ainda muito com foco no professor e no método expositivo. Além disso, alguns entrevistados chamaram a atenção para a questão da formação do docente, que não tinha sido voltada ao desenvolvimento de competências.

\section{Conclusões}

As habilidades a serem desenvolvidas nos alunos conforme proposta do curso em questão foram identificadas a partir da análise realizada por outros agentes sociais, e não a partir de processos próprios de análise da IES. 
Isso pode ter refletido na falta de alinhamento entre a intenção de se formarem empreendedores $e$ as habilidades a serem desenvolvidas.

Não havia no curso uma norma de competência que subsidiasse o desenho da formação, como propõe o enfoque da formação baseada em competências. Se existia algum tipo de norma de competência, esta seria de domínio dos próprios professores, não representando, portanto, o resultado de um processo articulado no curso como um todo, que alinharia requisitos do corpo docente, espaços, recursos didáticos, metodologias, recursos tecnológicos e as atividades profissionais aos critérios de realização.

Quanto ao processo de formação, verificou-se a presença de elementos que se articulam à proposta da Pedagogia das Competências. Entretanto, não se pode afirmar que a inserção da noção de competências no curso tenha representado uma real alteração no processo de formação. Um dos indícios relaciona-se ao fato de o processo de ensino e aprendizagem se encontrar ainda muito pautado no modelo de transmissão de conhecimentos em detrimento da formação de competências, o que ficou evidenciado na terceira fase da pesquisa. Outro indício refere-se ao processo de avaliação, que evidenciava que a aquisição do conhecimento era privilegiada no curso, pois havia tendência de os professores cobrarem do aluno somente o conhecimento, não a aquisição do saber fazer e do saber ser.

Além disso, alguns aspectos relevantes do modelo de formação baseado em competências precisavam ser tratados de maneira mais efetiva no curso. Entre eles chama atenção a questão da interdisciplinaridade, o uso de métodos que tirem o foco da transmissão de conhecimentos e se voltem ao desenvolvimento de competências, e a avaliação processual e formativa.

Por fim, cabe ressaltar a importância da articulação entre todos os elementos que representariam um processo de formação baseado em competências, o que pode se espelhado pela afirmação a seguir:

[...] quando a formação se orienta não só com base em perfis de competências previamente identificados, mas sim, organiza também processos de ensino/aprendizagem orientados à geração do saber, do saber fazer e saber ser, bem como à sua mobilização para enfrentar novas situações, então se estará diante de um processo de formação baseada em competências (VARGAS; CASANOVA; MONTANARO, 2001, p. 70, tradução nossa). 
Em termos conclusivos, havia indícios, de um lado, da presença de alguns dos elementos da Pedagogia das Competências no curso pesquisado; de outro, isso não significava que houvesse uma orientação sistematizada e articulada, de forma global, entre todos os elementos que compunham o processo de ensino-aprendizagem.

\section{The Teaching in Administration Courses Based on a Competency - Acquisition Approach}

\section{Abstract}

This paper aims to analyse the inclusion of the notion of competencies in undergraduate courses, considering a particular Business Administration course as its main object. This research is qualitative-descriptive, having a case study as its basis. Semi-structured interviews were conducted in all phases, with a total of five interviewees, comprising Course Coordinators, Pedagogy Coordinators, and a Consultant. Categories of analysis had been previously determined, and then data was analysed according to the content analysis method. The outcomes indicate a probable absence of explicitness as to the use of the following subjects competencies and skills; lack of articulation between the skills that are meant to be developed in students and the explicit intentions in students' formation; teachercentered learning; focus on knowledge transmission rather than on competency formation; difficulties to operate the model based on competency formation. It can be concluded that there was no indication of norms of competency serving as a basis for the formation process, despite the identification of skills to be revealed at the end of the course. On the one hand, there was some evidence of elements of a Pedagogy of Competencies in the course analysed. On the other hand, this did not mean that a whole articulated and systematic orientation was present in all the elements forming the teaching-learning process.

Key words: Teaching in Administration courses. Competency-acquisition Approach. Teaching-learning process. 


\section{Referências}

ARAÚJO, R. M. L. Desenvolvimento de competências profissionais: as incoerências de um discurso. Belo Horizonte, 2001. 192 f. Tese (Doutorado em Educação) - Programa de Pós-Graduação em Educação, Universidade Federal de Minas Gerais, 2001.

BECKER, G. V.; DUTRA, J. S.; RUAS, R. Configurando a trajetória de desenvolvimento de competências organizacionais: um estudo de caso em empresa da cadeia automobilística. In: DUTRA, J. S.; FLEURY, M. T. L.; RUAS, R. (Org.). Competências: conceitos, métodos e experiências. São Paulo: Atlas, 2008. p. 51-79.

BERGER FILHO, R. L. Currículo por competências. Disponível em: <http:/ /www.mec.gov.br/semtec/ensmed/FTP/currícompet.doc >. Acesso em: $10 \mathrm{fev}$. 2003.

BRASIL. Ministério da Educação. Secretaria de Educação Fundamental. Parâmetros curriculares nacionais: terceiro e quarto ciclos do ensino fundamental: introdução aos parâmetros curriculares nacionais. Brasília: MEC/ SEF, 1998. $174 \mathrm{p}$.

BRASIL. Ministério da Educação. Conselho Nacional de Educação. Câmara de Educação Superior. Parecer CNE/CES 0134/2003, de 4 de junho de 2003.

Diretrizes curriculares nacionais do curso de graduação em administração. Brasília, DF, 4 jun. 2003.

BRÍGIDO, R. V. Criação de uma rede nacional de certificação de competências nacionais. In: OIT-ORGANIZAÇÃO INTERNACIONAL DO TRABALHO.

Certificação de competências profissionais: "discussões". Brasília: OIT, MTE/FAT, 1999. p.49-126.

BOYATZIS, R. E. The competent manager. New York: John Wiley, 1982.

CENTRO DE GESTÃO EMPREENDEDORA. Manual de graduação. Belo Horizonte: [s.n.], 2003. 55 p.

CINTERFOR. Centro Interamericano de Investigación y Documentación sobre Formación Profesional. Las 40 preguntas más frecuentes sobre competencia laboral. Disponível em: <http://www.cinterfor.org.uy > . Acesso em: 11 ago. 2004. 
DIAS, G. B. et al. Revisando a noção de competência na produção científica em administração: avanços e limites. In: DUTRA, J. S.; FLEURY, M. T. L.; RUAS, R. (Org.). Competências: conceitos, métodos e experiências. São Paulo: Atlas, 2008. p. 9-30.

DUTRA, J. S. Competências: conceitos e instrumentos para a gestão de pessoas na empresa moderna. São Paulo: Atlas, 2008.

FERNANDES, J. et al. Diretrizes curriculares e estratégias para implantação de uma nova proposta pedagógica. Revista da Escola de Enfermagem da USP, São Paulo, v.39, n.4, p.443-449, 2005.

FLEURY, A.; FLEURY, M. T. L. Alinhando estratégia e competência. Revista de Administração de Empresas, São Paulo, v. 44, n. 1, p. 44-57, jan./mar. 2004.

GIL, A. C. Como elaborar projetos de pesquisa. São Paulo: Atlas, 1996.

GONCZI, A. Enfoques de educación y capacitación basada en competencia: la experiencia australiana. In: Seminário Internacional Formación Basada en Competencia Laboral: situación atual y perspectivas. México: CONOCER/OIT, 1996. p.69-77.

HANDFAS, A. Considerações sobre as mudanças nos processos produtivos e a formação profissional do trabalhador. In: REUNIÃO ANUAL DA ANPED, 24, 2001, Caxambu. Anais eletrônicos... Disponível em: < http:// www.anped.org.br>. Acesso em: 2 maio 2004.

JAVIDAN, M. Core competence: what does it mean in practice? Long Range Planning, v. 31, n. 1, 1998.

LE BOTERF, G. Desenvolvendo a competência dos profissionais. 3. ed. Porto Alegre: Artmed, 2003.

LEI, D.; HITT, M. A.; BETTIS, R. Competências essenciais dinâmicas mediante a metaaprendizagem e o contexto estratégico. In: FLEURY, M. T. L.; OLIVEIRA JR.; M. M. Gestão estratégica do conhecimento: integrando aprendizagem, conhecimento e competências. São Paulo: Atlas, 2001.

MERTENS, L. Competencia laboral: sistemas, surgimiento y modelos. Montevideo: Cinterfor, 1996. 
MORETTO, V. P. Planejamento: planejando a educação para o desenvolvimento de competências. 4. ed. Petrópolis: Vozes, 2009.

OIT - ORGANIZAÇÃO INTERNACIONAL DO TRABALHO. Certificação de competências profissionais: "discussões". Brasília: OIT, MTE/FAT, 1999.

PERRENOUD, P. Construir as competências desde a escola. Porto Alegre: Artes Médicas Sul, 1999.

Artmed, 2000.

. Pedagogia diferenciada: das intenções à ação. Porto Alegre:

PRAHALAD, C. K.; HAMEL, G. Competindo pelo futuro. Rio de Janeiro: Campus, 1995.

RAMOS, M. N. A pedagogia das competências: autonomia ou adaptação. 2. ed. São Paulo: Cortez, 2002.

ROPÉ, F.; TANGUY, L. (Org). Saberes e competências: o uso de tais noções na escola e na empresa. 4. ed. Campinas: Papirus, 2003.

RUÉ, J.; ALMEIDA, M. I.; ARANTES, V. A. (Org.). Educação e competências: pontos e contrapontos. São Paulo: Summus, 2009.

SANTOMÉ, J. T. Globalização e interdisciplinaridade: o currículo integrado. Porto Alegre: Artmed, 1998.

SELLTIZ, C. et al. Métodos de pesquisa das relações sociais. São Paulo: Herder, 1965.

SILVA, M. R. Currículo e competências: a formação administrada. São Paulo: Cortez, 2008.

TANGUY, L. Racionalização pedagógica e legitimidade política. In: ROPÉ, F;

TANGUY, L. (Org.). Saberes e competências: o uso de tais noções na escola e na empresa. 4. ed. Campinas: Papirus, 2003. p. 25-67.

TRIVIÑOS, A. N. S. Introdução à pesquisa em ciências sociais: a pesquisa qualitativa em educação. São Paulo: Atlas, 1987.

TRUJILLO, N. R. Selección efectiva de personal basada en competencias.

Revista do Serviço Público, ano 51, n. 3, p. 99-119, jul./set. 2000. 
VARGAS, F; CASANOVA, F; MONTANARO, L. El enfoque de competencia laboral: manual de formación. Montevideo: Cinterfor/OIT, 2001. 130 p.

YIN, R. K. Estudo de caso: planejamento e métodos. 2. ed. Porto Alegre:

Bookman, 2001.

ZABALA, A.; ARNAU, L. 11 ideas clave: cómo aprender y enseñar competencias. Barcelona: Graó, 2007.

ZARIFIAN, P. Objetivo competência: por uma nova lógica. São Paulo: Atlas, 2001. 